\title{
Paz y desarrollo: dos conceptos irreconciliables para las Mujeres Amazónicas del Ecuador
}

\section{Peace and Development: Two Irreconcilable Concepts for Amazon Women in Ecuador}

Artículo de investigación

Fecha de recepción: 29 de febrero de 2020

Fecha de aceptación: 24 de abril de 2020

\section{Para citar este artículo:}

Álvarez Lugo, Y. (2020). Paz y desarrollo: dos conceptos irreconciliables para las Mujeres Amazónicas del Ecuador. Campos en Ciencias Sociales, 8(2), 313-346. DOI: https://doi.org/10.15332/25006681/6021

\footnotetext{
Doctora en Estudios sobre Desarrollo por el Instituto Hegoa, Universidad del País Vasco upv/enu, Espańa; máster en Desarrollo y Cooperación Internacional por esta misma Universidad; licenciada en Derecho y en Humanidades por la Universidad Carlos III, Madrid, Espańa. Actualmente, es miembro del grupo de investigación Política, Derecho y Territorio (PODET) de la Universidad Nacional Abierta y a Distancia (Colombia) y participa en el Proyecto Pensamientos críticos sobre el desarrollo: teorias, enfoques y experiencias del Instituto Hegoa. Además, colabora con el Área de Derecho Internacional Público de la Universidad de La Laguna, Santa Cruz de Tenerife, Espańa. Correo electrónico: yesicala3@gmail.com
} 


\section{RESUMEN}

$\mathrm{Paz}$ y desarrollo son dos conceptos irreconciliables para las mujeres lideresas y dirigentes de la Amazonía norte, centro y sur del Ecuador. En este contexto, el desarrollo es sinónimo de neoextractivismo y, por lo tanto, supone la devastación de sus territorios y formas de vida en armonía con la Naturaleza. En este caso el consenso de las commodities toma forma bajo la amenaza constante de la Ronda Suroriente y las Rondas Intercampos, a partir de la cual entran a licitación bloques petroleros localizados en sus territorios ancestrales. El colectivo Mujeres Amazónicas —integrado al movimiento indígena ecuatoriano, pero como sujeto político con personalidad propia - exige el cumplimiento de su mandato. A través de este y de sus testimonios directos nos acercaremos a la comprensión de esta relación irresoluble entre paz y desarrollo, y reconoceremos las diferentes formas de violencia que este modelo extractivista imprime en sus cuerpos y territorios, por su posición como defensoras de la selva y como mujeres. Además, tomando como eje la historia de la Ronda Suroriente, abordaremos las disputas entre las diferentes jurisdicciones y territorialidades en conflicto, que combaten por mantener modos de vida en armonía con la Naturaleza o instaurar/profundizar el modelo desarrollista-economicista imperante.

Palabras clave: desarrollo, neoextractivismo, alternativas al desarrollo, Sumak Kawsay/buen vivir, conflictos ambientales y sociales, Naturaleza.

\section{Abstract}

Peace and Development are two irreconcilable concepts for female leaders and administrators in the northern, central, and southern Amazon of Ecuador. In this context, development is synonymous with neo-extractivism and, therefore, entails the devastation of their territories and ways of life in harmony with nature. In this case, the commodity consensus takes the shape of the constant threat of the South-East Round and the Intercampos Round, through which oil blocks located in their ancestral territories enter into tendering. The Amazon Women Collective - part of the Ecuadorian indigenous movement, but a political subject with its own personality - demands the fulfilment of its mandate. Through direct testimonies from some of the Collective's members and their mandate, we will come closer to understanding this irresolvable relationship between peace and development, and we will recognize the 
different forms of violence that this extractive model imprints on their bodies and territories, as a result of their position as defenders of the jungle and as women. In addition, taking the history of the South-East Round as an axis for inquiry, we will address the disputes between the different jurisdictions and territorialities in conflict, which fight to maintain lifestyles in harmony with nature or establish/deepen the prevailing developmental-economicist model.

Keywords: development, neo-extractivism, alternatives to development, Sumak Kawsay/ Good Living, environmental and social conflicts, nature.

\section{INTRODUCCIÓN}

La crítica al modelo desarrollista como instigador y contrario a la convivencia entre los seres que coexisten en la Amazonía ecuatoriana se presenta como eje del conflicto existente entre los pueblos indígenas y el Estado. El actual modelo de desarrollo impuesto en Ecuador, basado en el extractivismo, se encuentra en disputa con otras alternativas que propugnan la defensa de la vida en un sentido amplio y que se han venido agrupando bajo el término Sumak Kawsay. En este contexto, el colectivo Mujeres Amazónicas se ha constituido como un grupo diferenciado dentro del más amplio Movimiento Indígena del Ecuador, adquiriendo cada vez mayor protagonismo en la lucha contra el extractivismo y las violencias machistas que este modelo de desarrollo trae aparejadas.

La Constitución ecuatoriana de 2008 se posiciona dentro del llamado constitucionalismo plurinacional en el sentido en el que se inscribe de manera explícita en un proyecto de descolonización y afirma el principio de pluralismo jurídico, la igual dignidad de los pueblos y culturas, y la interculturalidad (Yrigoyen, 2015, pp. 161-167). No obstante, tal y como afirma Rachel Sieder (2015, pp. 153-154), a pesar de este nuevo constitucionalismo, el Gobierno ecuatoriano continúa apostando por un modelo de desarrollo extractivista basado en la expoliación de recursos naturales. Así, y a pesar de contar con una Constitución que potencialmente podría suministrar una herramienta jurídico-política de lucha —en defensa de los territorios indígenas, de sus propios sistemas jurídicos y en contra el modelo de desarrollo convencional—, los pueblos 
indígenas del Ecuador y sus territorios se siguen enfrentando a las amenazas del neoextractivismo y a la imposición del derecho del Estado. Y es que no debemos ignorar que a la Constitución de Montecristi se le pueden aplicar dos lecturas principales: una desarrollista y otra posdesarrollista; siendo la primera la dominante en la realidad política y jurídica por la que ha apostado el Estado en más de una década de vigencia.

Así, desde su posición de poder, el Estado ha inclinado la balanza interpretativa del texto constitucional hacia una lectura desarrollista y monista, donde los derechos colectivos de los pueblos indígenas, el pluralismo jurídico de tipo fuerte en el que los sistemas jurídicos indígenas y el Derecho del Estado están en la misma posición jerárquica, y las alternativas al desarrollo se ven mermadas a favor de una mercantilización aún mayor de la vida y una profundización del modelo de desarrollo convencional-economicista.

Con el tiempo hemos sido testigos de cómo se ha vaciado la Constitución de este sentido posdesarrollista a través de la normativa infraconstitucional, con leyes como la Ley Orgánica de Tierras Rurales y Territorios ancestrales (Ley 0, Registro Oficial Suplemento 711, 14 de marzo de 2016) la Ley Orgánica de Garantías Jurisdiccionales y Control Jurisdiccional (Ley 0, Registro Oficial Suplemento 52, 22 de octubre de 2009, reformas en el ámbito del Derecho Penal y del Derecho Procesal Penal, la Ley Orgánica de Educación Superior de 2010 por la cual se eliminó la Universidad Intercultural de las Nacionalidades y Pueblos Indígenas (Uiaw) (Ley 0, Registro Oficial Suplemento 298, 12 de octubre de 2010), y —unas de las que más recelos levanta- la Ley de Minas (Ley 45, Registro Oficial Suplemento 517, 29 de enero de 2009) y la Ley Orgánica de la Planificación Integral de la Circunscripción Territorial Especial Amazónica (Ley s. n., Suplemento del Registro Oficial 245, 21 de mayo de 2018).

Además de dicho proceso de desconstitucionalización, observamos cómo la cultura jurídica imperante en el país — de escasa impronta intercultural y de tradición legalista- y la directa violación de la normativa constitucional en materia de consulta previa prelegislativa sostiene y da continuidad al neoextractivismo y, con él, al despojo de territorios y cuerpos. Así, no hay más que leer los Planes Nacionales de Desarrollo o Planes Nacionales para el Buen Vivir de la Secretaría Nacional de Planificación y Desarrollo (Senplades, 2007; 2009; 2013; 2017) para darnos cuenta de que los 
mismos no son más que una clara hoja de ruta hacia la profundización del modelo de desarrollo convencional-economicista que devasta vidas, culturas y ecosistemas.

A partir de esta realidad impuesta se dibuja un escenario donde el conflicto y la amenaza a la sostenibilidad de la vida se constituyen como el eje vertebrador de la vida cotidiana de los pueblos indígenas que resisten a este modelo. Y es que debemos comprender que la guerra proclamada entre el modelo desarrollista y las alternativas se libra diariamente en territorios donde hay que convivir - mejor sería decir sobrevivir - con la amenaza del despojo, violencias machistas, criminalización y enfermedades causadas por la contaminación del medio. Es decir, la acumulación por desposesión de las que nos habla Harvey (2005) para referirse a la lógica de crecimiento y beneficios progresivos que las grandes corporaciones mantienen a costa de los derechos de las mayorías sociales y la destrucción de pueblos y culturas, se materializa en espacios concretos como es, en este caso, la Amazonía ecuatoriana.

En este escenario, la promesa de los discursos oficiales sobre desarrollo y progreso, como un estadio libre de carencias y con las necesidades básicas cubiertas, se desvanece. En su lugar hay dolor, sufrimiento y sacrificio. Palabras todas ellas que, como veremos, utilizan continuamente las Mujeres Amazónicas para describir una vida que está marcada por la defensa de sus territorios y de los seres que coexisten en él. Es por todo ello que afirmamos que en el contexto de la Amazonía ecuatoriana paz y desarrollo se muestran como dos conceptos irreconciliables. Y eso a pesar de que estamos aludiendo a una idea de paz imperfecta, entendida esta como "aquellas situaciones en las que se consigue el máximo de desarrollo de las capacidades humanas de acuerdo con las condiciones sociales y personales de partida” (Muñoz, 2001).

Lo anterior significa concebir que la paz "está en permanente construcción, es cotidiana y ubicua, perfectible, inacabada y convive con los conflictos y, aunque pueda parecer contradictorio, con la violencia” (Jiménez, 2018, pp. 21-22). Esta paz imperfecta no parecería darse en la Amazonía ecuatoriana, en el sentido que — como se verá a partir de los testimonios de las Mujeres Amazónicas - se vive en una constante alerta y desasosiego, emociones que se unen a las consecuencias directas de la contaminación y enfermedades de las empresas extractivas en territorios y cuerpos. 
Para acercarnos un poco a la lucha de estas dirigentes y lideresas de la Amazonía ecuatoriana - que son, a su vez, representantes de otras mujeres que igualmente están resistiendo- y entender la complejidad de sus luchas, partiremos de intentar comprender cómo la defensa del territorio, de los propios sistemas jurídicos y de sus modos de vida en armonía con la Naturaleza van de la mano. Para ello nos valdremos de entrevistas realizadas a quince dirigentes y lideresas de las siete nacionalidades de la Amazonía ecuatoriana: achuar, andoa, kichwa, sapara, shiwiar, shuar y waorani.

Estas entrevistas fueron realizadas durante los días que las Mujeres Amazónicas esperaban frente al palacio de gobierno para entregar su mandato. Luego, nos acercaremos a la historia de la Ronda Suroriente, una ronda petrolera que mantiene en una alerta constante a las nacionalidades y pueblos de la Amazonía ecuatoriana. Se trata de la amenaza constante del desarrollo y de la imposición del monismo jurídico que avala sus prácticas, además de un claro ejemplo que ilustra cómo el consenso de las commodities, del que nos habla Svampa (2013), lejos de ser una teoría abstracta, tiene corporalidad. Después analizaremos el Mandato de las Mujeres Amazónicas (2018), tomándolo como un documento en el que quedará plasmada en síntesis la conjunción de luchas que se entrelazan y que derivan, todas ellas, es una misma cuestión: la defensa de la vida y convivencia armónica entre seres que coexisten contra la devastación de un modelo de desarrollo economicistaextractivista que viola derechos y mata la vida. A partir de dicho documento intentaremos acercarnos a la intersección de afectaciones e impactos que el desarrollo causa en estas mujeres por el hecho de ser mujeres y, además, por ser duras y fieles defensoras de la selva.

\section{LA GUERRA QUE DECLARA EL DESARROLLO: DISPUTAS ENTRE JURISDICCIONES Y TERRITORIALIDADES EN LA AMAZONÍA ECUATORIANA}

La Amazonía es una región que ha sido intervenida por los pueblos indígenas, pero estos, generalmente, lejos de haber interaccionando con esta Naturaleza de manera devastadora — como sí lo hace el modelo desarrollista-extractivista—, lo han 
hecho de una manera respetuosa ${ }^{1}$ y a través de principios como la reciprocidad y la complementariedad, en el marco de una territorialidad en el que el propio territorio se configura como un actor político más (Ulloa, 2014).

Esta interacción, en la que los pueblos han gestionado los recursos y el conjunto de sus territorios, está regulada por sus propios sistemas jurídicos y por la lógica territorial en los que estos se basan. Por lo tanto, defender el territorio va unido indisolublemente a la defensa de gestionar y legislar ese mismo territorio de acuerdo con los sistemas jurídicos indígenas, que han permitido y legitimado esos modos de vida en armonía con la Naturaleza y han hecho que hoy hablemos de la Amazonía como un lugar megadiverso.

En este sentido, cuando hablamos de un conflicto entre los pueblos indígenas, de un lado, y el Estado y las empresas transnacionales, por otro, estamos hablando de un conflicto jurisdiccional. Dicho de otra manera, el enfrentamiento entre estos diferentes agentes se debe a la pretensión de cada uno de ellos de ejercer su propia jurisdicción y, con ello, gobernar y gestionar este espacio y sus recursos de manera autónoma a partir de sus propios sistemas normativos. En el caso indígena, dicha pretensión cuestiona el monismo jurídico del Estado y, por lo tanto, la legitimidad de la imposición del derecho estatal a los territorios y personas indígenas que se guían por otro sistema jurídico y otras autoridades. Asimismo, cuestiona la legitimidad de los permisos, planes y licencias que autorizan que en sus territorios se les impongan actividades extractivas, empresariales, militares o de otra índole, sin su consentimiento y sin la observancia debida a sus normas, medio y cultura. A este respecto, Gloria Ushigua, presidenta de la Asociación de Mujeres Saparas, afirmó:

Yo tengo un territorio grande, yo soy una cultura tan chiquita. Y dentro de mi territorio hay dos bloques, 83, 79 ya está vendido a Andes Petroleum por Rafael Correa. Pero tienen dinero no está explotado y queremos que quede

1 Advertencia sobre la romantización de los pueblos indígenas: sabemos que no todos los pueblos indígenas se relacionan o se han relacionado de manera armónica con la Naturaleza. Los pueblos y comunidades indígenas son enormemente heterogéneos y no es posible generalizar. No obstante, y dicho esto, sí es cierto que en las áreas verdes del planeta donde viven pueblos indígenas estos — en su mayoría — mantienen modos de vida en armonía con la Naturaleza. 
bajo tierra. A nosotros no comemos ese dinero [...]. Y no vamos a ir cárcel porque es nuestro derecho reclamar que quede bajo tierra el petróleo. (G. Ushigua, comunicación personal, 12 de marzo de 2018)

En este marco de razonamiento, y para los indígenas, da exactamente igual lo que diga la Constitución, las leyes o los instrumentos internacionales; los territorios indígenas son regiones ancestrales y, por lo tanto, estos se deben regir por el derecho propio y por las obligaciones y principios que este establezca. El respeto a la pluralidad y diversidad de los modos de vida indígenas no está garantizado en un contexto de dominio del derecho estatal. Es por ello que estos pueblos focalizan sus luchas contra el Estado y su doctrina jurídica monista, así como contra las empresas transnacionales y su pluralismo jurídico liberal-desarrollista, que superpone en estos territorios el derecho corporativo global en alianza con el monismo jurídico del Estado (ÁlvarezLugo, 2017).

En este sentido es necesario entender que, en el marco de las disputas territoriales entre pueblos indígenas, Estado y empresas transnacionales, confluye la pretensión de cada agente por el control jurídico de estos territorios y recursos. En dicha pretensión subyace una idea de modelo de vida y de sociedad; es decir, el conflicto se enmarca en la perpetuación y profundización del modelo de desarrollo convencional dominante actualmente o en hacer valer otras lógicas y modelos alternativos a este, como se intenta en el caso de las Mujeres Amazónicas.

En conclusión, podemos sostener que la reivindicación territorial tradicional de los movimientos indígenas —aquellos que defienden la Naturaleza y sus modos de vida en armonía con esta - cuestiona precisamente el monismo jurídico imperante, asociado con la hegemonía del Estado-nación, y el modelo de desarrollo convencional depredador de recursos naturales y destructor de ecosistemas. A través de las reivindicaciones por hacer valer su derecho colectivo a sus tierras, territorios y recursos naturales, estos movimientos indígenas en defensa de la Naturaleza y de sus modos de vida se oponen al modelo de Estado monista y desarrollista dominante, haciendo valer otras formas, otros modelos y, en definitiva, manteniendo la práctica concreta de alternativas al desarrollo. 
Paralelamente, y de manera intrínsecamente unida, debemos entender que el núcleo de este conflicto jurisdiccional está determinado por las diferentes lógicas de territorialidad que entran en disputa entre los diferentes actores implicados. Por un lado, tenemos a las grandes corporaciones o empresas transnacionales enmarcadas en un paradigma economicista, a los Estados que conciben sus recursos naturales como elementos estratégicos para el progreso del país dentro del consenso de las commodities (Svampa, 2013, p. 43) y los pueblos indígenas que defienden una altergeopolitica del territorio (Ulloa, 2014). Para Maristella Svampa (2013, pp. 32-36) del consenso de Washington, asentado sobre la valorización financiera, se pasó al consenso de las commodities, que hace alusión a un nuevo orden económico y político-ideológico basado en la demanda de materias primas de los países centrales y emergentes, que impone un modelo de desarrollo neoextractivista y, por lo tanto, una mayor profundización de la dinámica de la desposesión. En este marco, no es debatible y, por lo tanto, no se concibe que se cuestione sobre la pertinencia o no de explotar territorios ricos en recursos mineros y petroleros, como es el caso de la Amazonía ecuatoriana.

Para Svampa (2013, p. 36) esta idea de consenso marca el límite de lo pensable/ debatible, de tal modo que los daños producidos a los pueblos indígenas y a sus territorios son secundarios o colaterales, y que deben asumirse en pro de un bien mayor, que es la mejora de las mayorías sociales que se verán beneficiadas por el desarrollo. Pero, en ningún caso, es factible asumir las demandas de los pueblos indígenas de que en estos territorios se mantengan modos de vida en armonía con la Naturaleza que, por definición, son incompatibles con las actividades extractivas que impone este modelo. En este contexto el interés público se justifica en aras del bien común y mejor vivir de las mayorías sociales, lo que Teresa Cunha (2019) apunta como "violaciones de los derechos humanos para garantizar los derechos humanos"; una perversión del desarrollo que, sin embargo, para las teorías del posdesarrollo es consustancial al propio discurso y a la propia empresa desarrollista (Acosta, 2013; Escobar, 2012; Rist, 2002; Esteva, 2009).

$\mathrm{Al}$ respecto, Sandra Tukup, presidenta shuar de la Comunidad Chiwias del Cantón Logroño, Morona Santiago, afirmó: 
Si ellos están destruyendo, no es desarrollo; viene a ser una gran pérdida. No es un desarrollo, sino que van a sacar el petróleo y la mina. Van a destruir todo. Están destruyendo el bosque, la vida de los animales que viven allí, la biodiversidad. Están destruyendo ¡todo! Queda la tierra inerte, la gente perjudicada, la gente muere de enfermedad. Todo, el aire, el agua contaminada. ¿De qué desarrollo habla? Es una quiebra total, yo digo. (S. Tukup, comunicación personal, 22 de marzo de 2018)

En el mismo sentido, se expresó Alicia Cahuiya, lideresa waorani y exvicepresidenta de la Nacionalidad Waorani del Ecuador (Nawe):

Nosotros defendemos la vida y la Naturaleza. [...] ¡Mucho hemos perdido y ahora quieren sacar más petróleo! Nosotros no queremos que saquen más petróleo en Yasuní, queremos que se nos dé el territorio para poder vivir con los hermanos taromenanes, que seamos en paz un día, para no morir más en esta selva del Yasuní. Porque cada vez que entra la petrolera nos han reducido nuestros territorios, nos han enfrentado dos grupos waorani taromenanes matando la vida. (A. Cahuiya, comunicación personal, 12 de marzo de 2018)

Por otro lado, tengamos presente que al ponerse en cuestión lo incuestionable por parte de los pueblos indígenas se traspasa el mero marco del conflicto ambiental, y ello debido a que lo que está en juego es algo mucho más complejo que el cuidado o no del medioambiente. En estos casos los impactos o afectaciones superan el ámbito biofísico. Lo que está en riesgo en esta guerra contra el neoextractivismo es toda una lógica territorial o como lo denomina Ulloa (2014) una "alter geografía del territorio". Así, el modelo desarrollista ataca los territorios indígenas y las múltiples relaciones que se dan en este, que no se circunscriben únicamente al mundo de lo humano, sino que integra otras dimensiones o mundos diversos.

Aquí debemos hacer un esfuerzo por comprender que para los pueblos indígenas el territorio es una realidad más dinámica e integral (abarca el aire, suelo y subsuelo). Además, se concibe como un ente vivo en interacción permanente y constante con una gran cantidad de procesos y de relaciones con otros seres, humanos y no humanos. El Pueblo Originario Kichwa de Sarayaku (2018) lo expresa con estas palabras: 
Kawsak Sacha [selva viviente] es un ser vivo, con conciencia, constituido por todos los seres de la selva, desde los más infinitesimales hasta los más grandes y supremos. Incluye a los seres de los mundos animal, vegetal, mineral, espiritual y cósmico, en intercomunicación con los seres humanos brindándoles a estos lo necesario para revitalizar sus facetas psicológicas, físicas, espirituales, restableciendo así la energía, la vida y el equilibro de los pueblos originarios. Es en las cascadas, las lagunas, los pantanos, las montańas, los ríos, los árboles y otros lugares del territorio, donde los Seres Protectores de Kawsak Sacha habitan y desarrollan una vida propia, semejante a la de los seres humanos. El Kawsak Sacha transmite los conocimientos al yachak para que interactúen en el mundo de los seres protectores de la selva, con el fin de mantener el equilibro de la Pachamama, sanar a las personas y a la sociedad. Este conocimiento es metódicamente mantenido y transmitido a las nuevas generaciones.

Así, el territorio se configura como un actor social más. A partir de ahí se constituye una política local territorial que genera sentido de pertenencia, de identidad y emociones que construyen al ser geográfico; es decir, el cómo se es en un territorio, cuál es el lugar que se ocupa en este o, en definitiva, cómo se está imbricado en este espacio y cuáles son los deberes que se tienen por ello (Ulloa, 2014). Estamos hablando de relaciones ontológicas y, por lo tanto, el nivel de análisis de estudios o evaluaciones de impacto ambiental frente a megaproyectos — por muchos esfuerzos que se tomen por incluir la dimensión cultural, espiritual y simbólica - no llega a ser fiel reflejo de las afectaciones reales sobre los pueblos y las personas que lo conforman.

En definitiva, la territorialidad de los pueblos indígenas, como ya hemos explicado, va unido al autogobierno y al ejercicio de sus propios sistemas jurídicos y, por lo tanto, no se comprende con restricciones a su jurisdicción. Dentro de esta lógica, la autodeterminación adquiere una centralidad máxima que es amenazada por las pretensiones de agentes externos (Estado y empresas transnacionales) que imponen visiones generando — más que conflictos_ verdaderas guerras contra la vida. 


\section{La Ronda Suroriente: La AMENAZA DEL DESARROllo EN EL NORTE, CENTRO Y SUR DE LA AMAZONÍA}

La Ronda Suroriente o XI Ronda tiene una historia de años. Ha sido una amenaza latente durante mucho tiempo, por lo que el adjetivo de novedosa no le es aplicable. Su denominación como XI Ronda y sus bloques petroleros a licitación datan del año 2012, con el Gobierno del expresidente Rafael Correa, pero el inicio de su cronología se retrotrae hasta los años ochenta. Entonces, ¿qué es lo que hace que esta Ronda tan antigua motive a las Mujeres Amazónicas a iniciar su marcha en 2018 y a elaborar su Mandato (aún vigente)? Precisamente su vuelta a la actualidad, con el anuncio del Gobierno de Lenin Moreno de lanzar a licitación los bloques del suroriente ecuatoriano (El Universo, 2018).

Este anuncio hace saltar las alarmas por aquel entonces entre las Mujeres Amazónicas y actualmente, en nuestros días, vuelve a revelarse: a lo largo de 2020 entrarán a licitación los bloques petroleros del suroeste de la Amazonía y los de la Ronda Intercampos II (Agencia EFE, 2019). En este punto es importante conocer la historia de esta amenaza, ya que ello nos permite acercarnos a lo que supone en la realidad el consenso de las commodities del que nos habla Svampa (2013), y entender cómo la lógica territorial y el modelo de desarrollo que se impone desde el monismo del Estado en alianza con el derecho corporativo global (Hernández-Cervántes, 2014; Hernández-Zubizarreta, 2015) se materializa interviniendo en los cuerpos y en los territorios.

En un primer momento, la Secretaría de Hidrocarburos diseñó veintiún bloques petroleros de aproximadamente 200000 hectáreas cada uno. Las primeras informaciones en prensa indican que siete de estos bloques serían destinados a empresas estatales de países fraternos y había indicios de que estas empresas pudieran ser Enap, Andes Petroleum, Agip, Sinopec, Pdvesa, Turkish Petroleum, Petrovietnam, Corea Nacional Oil Company, Ancap y Ecopetrol (Melo 2012, pp. 105-106). Sin embargo, en informaciones posteriores, se señalaba que de estos veintiún bloques, cinco se destinarían a futuras licitaciones (bloques 74, 75, 76, 82 y 85), tres serían adjudicados directamente a la empresa estatal Petroecuador (bloques 28, 78 y 86 ) y los bloques restantes (13 en total) se pondrían a licitación en esta XI Ronda Petrolera (29, 22, 70, 71, 72, 73, 77, 79, 80, 81, 83, 84, 87) (Secretaría de Hidrocarburos, 2013). 
No obstante, en nuevos documentos oficiales ascenderían a 16 los bloques puestos a licitación, pues en los últimos informes se incluyen los bloques 76, 82 y 85, que en un primer momento quedan pendientes para posibles nuevas rondas (Secretaría de Hidrocarburos, 2018).

La especialista en hidrocarburos, Alexandra Almeida ${ }^{2}$ (2018) de Acción Ecológica, nos suministra las claves para entender cómo una ronda anunciada en 2012 sigue intentándose años después, a pesar de sus repetidos fracasos. No obstante y en primer lugar, una de las cuestiones que debemos considerar de manera previa es que el norte de la Amazonía se encuentra explotado desde hace décadas y que es el destino de la Amazonía Centro y Sur lo que se dirime con el éxito o no de las licitaciones de la XI Ronda. No obstante, las mujeres de las nacionalidades, pueblos, comunidades y comunas de los territorios ya explotados por la industria petrolera se unen a esta lucha para expresar su oposición a la continuación de la explotación en sus territorios, así como a la ampliación de campos y pozos petroleros en estos. No hay que olvidar ni ignorar que la licitación de los llamados campos marginales o campos menores ${ }^{3}$, así como la licitación de los intracampos, supone el aumento de la explotación de los pozos ya existentes o la explotación de nuevos pozos.

La historia petrolera del Ecuador comienza en los años veinte y se acrecienta a principios de los setenta, con la llegada de Texaco a la Amazonía Norte, incrementándose notablemente en los años 80 . Ya en los noventa se había entregado toda la parte norte de la Amazonía y el Bloque 10 (en el Centro, a Agip Oil), así que en la VIII Ronda se pone a licitación nueve bloques del Sur, de los cuales solo interesaron tres: 31, 23 y 24. No obstante, la resistencia indígena del pueblo Sarayaku y de las organizaciones shuar FIPSE (actual NASHE) y FICSH, por un lado, y la organización achuar Finae (actual NAE) por otro, impidieron la entrada de las empresas a los bloques 23 y 24 (Melo 2012, pp. 108-110; Corte Interamericana de Derechos Humanos, 2012).

2 Se hace necesario agradecer a Alexandra Almeida su ayuda en el trabajo de entender la historia de la XI Ronda petrolera, pues sin ella no hubiese sido posible la clara comprensión de esta.

3 Los campos marginales o menores son campos petroleros pequeños que han estado en manos del Estado y que producen menos del $1 \%$ de la producción total nacional. Lo que necesitan estos campos, que tienen una producción pequeña, es que ingrese inversión para que pueda subir la producción. La empresa que entra gana el excedente de producción y el campo sigue siendo propiedad del Estado. 
Tras una IX Ronda declarada desierta (Secretaría de Hidrocarburos, 2013) y la X Ronda de campos marginales, se lanzó a licitación los bloques del Suroriente el 28 de noviembre de 2012, para lo que se contaba ya con el Decreto Ejecutivo 1247, con el que entró en vigor el Reglamento para la Ejecución de la Consulta Previa, Libre e Informada en los Procesos de Licitación y Asignación de Áreas y Bloques Hidrocarburíferos (Ecuador, 2012). Este reglamento violaba el derecho a la consulta prelegislativa, ya que, además de no haber contado con la participación del Movimiento Indígena y de sus organizaciones para su formulación, no contemplaba la posibilidad de que las comunas, comunidades, pueblos y nacionalidades se negaran a ser consultadas (Acción Ecológica, 2018). El mismo día del lanzamiento de la XI Ronda, en el Hotel Marriott de Quito, se organizó una gran protesta indígena a las afueras del edificio. Estas se repitieron en varias ciudades del Mundo — Bogotá, Houston, París, Pekín y Calgary— donde el Gobierno celebraba reuniones para ir a ofrecer sus bloques (El Norte, 2013).

El 28 de noviembre de 2013, justo un ańo después del lanzamiento de la XI Ronda, tendría lugar la apertura de sobres con las ofertas aportadas por las empresas para la licitación de los bloques. A la cita acudió la empresa china Andes Petroleum (interesada en los bloques 79 y 83), la española Repsol (interesada en el bloque 29), la estatal chilena Enap y la bielorrusa Belorusneft (El Telégrafo, 2013). Estas dos últimas tenían un convenio con la estatal Petroecudor para explotar el bloque 28, así que, a pesar de acudir a la cita, no había información de que estuviesen interesadas en la explotación de los bloques licitados. Tras finalizar la reunión, los embajadores de Chile y Bielorrusia salieron por la puerta principal, donde estaban apostados los indígenas defendiendo sus derechos territoriales. Al conocerse la identidad de estos, un hombre achuar agredió a uno de los embajadores con su lanza, sin mayores consecuencias (La República, 2013).

Todo este revuelo desvió la atención del fracaso de la XI Ronda hacia la violencia de los indígenas y comenzó una campaña de descrédito y persecución. Fue en este contexto cuando a la Fundación Pachamama se la acusó de incitación a la violencia y la clausuraron (El Ciudadano, 2013). Ese mismo año, en octubre 2013, las Mujeres Amazónicas realizaron su primera marcha contra la Ronda Suroriente. Ellas salieron de la ciudad de Puyo el 12 de octubre y llegaron a Quito cuatro días después para expresar su rechazo a la explotación petrolera en sus territorios (El País, 2013). 
Esta primera marcha contra la Ronda Suroriente estuvo precedida por el Primer Encuentro de Mujeres de las Organizaciones Indígenas Amazónicas por la defensa de la vida, el territorio y el Buen Vivir, que se celebró en la ciudad de Puyo cuatro meses antes de la marcha hacia la capital. En este encuentro se estableció la Agenda de Mujeres Indígenas frente al extractivismo, la cual contenía tres ejes de acción: el fortalecimiento organizativo de las mujeres, la resistencia al extractivismo y la construcción de otro modelo de desarrollo (Vallejo-Real y García-Torres, 2017, pp. 16-17). Luego, ya en el mes de octubre, se realizó la Asamblea Mujeres en Vigilia por la Vida, en la cual se elaboró un manifiesto - que podríamos considerar el antecedente del actual Mandato- y decidieron marchar hacia Quito para reivindicar sus derechos. En esa ocasión, el presidente del momento, Rafael Correa, no las recibió. Pese a esto, las Mujeres Amazónicas se presentan desde el comienzo de la resistencia como un actor de gran legitimidad, como un interlocutor fiel a su posicionamiento en contra del extractivismo y de defensa de sus territorios, sistemas jurídicos y modos de vida en armonía con la Naturaleza.

Sin apenas noticias del futuro de la XI Ronda Petrolera, se acaba el año 2014, 2015, $2016^{4}$ y 2017. Finalmente, llegó el 2018 y el anuncio del ministro de Hidrocarburos Carlos Pérez García el 27 de febrero de 2018 de que se lanzaría en el segundo semestre del año la XI Ronda Petrolera con la modalidad de contratos de participación y que empresas tan importantes como Exxon y Shell estaban interesadas (El Universo, 2018). Dicho anuncio se produjo en medio de las negociaciones entre el Gobierno y la CONAIE, un proceso de diálogo que empezó en julio de 2017 (El Comercio, 2017a) y que dio unas pequeñas dosis de esperanza al Movimiento Indígena en diciembre de 2017, cuando el ejecutivo anunció que no daría más concesiones mineras ni petroleras sin que fuera respetado el artículo 57 de la Constitución (El Comercio, 2017b). Pronto estas esperanzas se desvanecieron, y hasta la actualidad la indignación no ha dejado de aumentar en el Movimiento Indígena por la falta de cumplimiento de los compromisos.

A lo largo de estos años, las Mujeres Amazónicas han permanecido activas en la defensa de sus territorios y en la elaboración de una hoja de ruta propia como mujeres, la cual iría de la mano con una agenda más amplia de lucha contra el extractivismo

4 En enero de 2016, la empresa china Andes Petroleum firmó dos contratos para los bloques 79 y 83, en los que aún no ha empezado a actuar. Noticia publicada en Andes (2016). 
común al Movimiento Indígena del Ecuador. Entre los diversos encuentros y movilizaciones se destaca el yaku chaski, una práctica realizada por varias de las Mujeres Amazónicas, que consistía en la visita a las comunidades ribereñas para ser testigos de la contaminación causada por la industria extractiva y para advertir de sus impactos en aquellas zonas donde aún no se hubiese instalado esta industria (VallejoReal y García-Torres, 2017, p. 19).

Por lo tanto, se van creando sinergias y confluencias en los diferentes espacios de diálogo y encuentro entre estas lideresas y dirigentes. Cuando el Gobierno lanza la Ronda Suroriente, ya las Mujeres Amazónicas son un grupo fortalecido, con personalidad política propia, cuya agenda de género y de defensa del territorio contra el extractivismo se encuentra respaldada por las mujeres de base. Así, decidieron y aprobaron en asamblea redactar el Mandato de las Mujeres Amazónicas Defensoras De la Selva de las Bases frente al Extractivismo y marcharon hacia Quito para entregarlo al Gobierno.

No obstante, tras dos años de la Marcha de las Mujeres Amazónicas y de la entrega de su Mandato al presidente de la República Lenin Moreno, el fantasma de la Ronda Suroriente y las Rondas Intercampos sigue presente. A finales del 2019, el ministro de Energía y Recursos Naturales no Renovables, José Augusto, indicó en una rueda de prensa que la producción petrolera del país era la base fundamental de la economía y que para mejorar su producción se convocaría la Ronda Suroriente y la Ronda Intercampos II (EFE, 2019). Es necesario tener en cuenta que la meta del Gobierno ecuatoriano era tener una producción de 700000 barriles de petróleo diarios para el 2021, pero esta cifra tuvo que rebajarse a 580000 barriles debido a que en el 2018 y el 2019 no se pudo entrar en todas las áreas que estaban contempladas en el plan inicial del Ejecutivo.

Así, — por presiones por parte del Movimiento Indígena, en el que destaca la resistencia waorani- en el Bloque 43 Iтт (Ishpingo, Tambococha y Tiputini) solo se pudieron intervenir las plataformas A y B de Ishpingo — que bordea el área intangible del Yasuní y que sirve de protección a los pueblos indígenas en aislamiento voluntario-, y la explotación de los bloques 86 y 87 incluidos en la Ronda Suroriente quedó paralizada (El Comercio, 2019). No obstante, el Gobierno está predispuesto a subir la producción petrolera, para lo cual ha abandonado la Organización de Países 
Exportadores de Petróleo (OPEP) (El Universo, 2020), y ha anunciado que explotará Ishpingo, impulsará la ronda Suroriente y garantizará las inversiones. Ello nos dibuja un próximo escenario de resistencia ante el extractivismo por parte del Movimiento Indígena en general y de las Mujeres Amazónicas en particular.

Además, no debemos olvidar que tras el paro de octubre y los disturbios ocasionados en contra del llamado paquetazo, con el que se logró derribar el decreto 883 (que elimina el subsidio a los combustibles), el Movimiento Indígena integrado en el Parlamento de los Pueblos ha entregado al Gobierno una propuesta económica que no está siendo valorada. La negociación entre Movimiento Indígena y Gobierno está paralizada lo que, con anuncios como el de reactivar la Ronda Suroriente, no se hace sino incrementar la tensión.

\section{ViOLENCIAS E IMPACTOS DEL MODELO DE DESARROLLO neoextractivista a Través del Mandato de las Mujeres Amazónica}

Con la entrega de su Mandato en 2018, las Mujeres Amazónicas marcaron un punto de inflexión en la instauración de un espacio de diálogo propio. En este espacio son interlocutoras directas frente al presidente de la República como representantes de las mujeres de la Amazonía y como defensoras de la selva. Se identifican como firmes opositoras al extractivismo y al escenario de guerra continua contra la vida que el modelo desarrollista instaura en sus territorios. Y es que este carácter de firmeza es un elemento que estas dirigentes y lideresas subrayan junto con su papel de madres.

En palabras de Catalina Chumpi, dirigente shuar de la Coordinadora de Organizaciones de las Nacionalidades Amazónicas del Pastaza y presidenta de las siete nacionalidades de la Provincia de Pastaza:

Porque los hombres se venden, ellos por un trago. Nuestras autoridades a veces se venden cuando les ofrecen algún regalo. Nosotros no. Las mujeres somos bien positivas. Nosotros, las mujeres somos de una firme posición, en 
la cual nosotros no vamos a permitir, aunque los hombres hayan hecho sus negociados. No vamos a permitir, nosotros vamos a estar pendientes como mujeres, porque nosotros tenemos hijos. (C. Chumpi, comunicación personal, 13 de marzo de 2018)

Por su parte, Ena Santi, lideresa del pueblo Sarayaku y exdirigente de Mujeres del Pueblo Sarayaku explica:

Hemos venido acá desde la Amazonía ecuatoriana, las mujeres que siempre estamos unidas, siempre estamos en la lucha, siempre estamos gritando, siempre estamos caminando, cargando nuestros hijos, al lado nuestros hijos. [...] Tal vez los que viven ciudad dicen que las mujeres amazónicas no tienen pensamiento, no tienen idea y no pueden luchar. ¡No es así compañeras! Las mujeres indígenas somos capaces de luchar sangre a sangre compañeras. (E. Santi, comunicación personal 15 de marzo de 2018)

Y en esta misma línea se pronuncia Alicia Cahuiya, lideresa waorani y exvicepresidenta de la Nawe:

Por eso nosotros hemos caminado para dar ese mensaje, porque nosotros también preocupamos como una madre, donde nuestros hijos puedan nadar limpio, puedan coger las frutas limpios, y ahora están contaminados la mayoría de la Amazonía del Norte. [...] Para entrar más petróleo ya no podemos dar más permiso como mujeres. A nosotros sí nos duele como mujeres compartir nuestra tierra, nuestro río. (A. Cahuiya, comunicación personal, 12 de marzo de 2018)

Salomé Aranda, dirigente de la Mujer de la Comuna Moretecocha, concluye:

Por esas razones nosotros estamos aquí, porque nuestra vivencia ahí en la Amazonía para sobrevivir, es el producto y los peces del agua y los animales de la selva y nuestro mercado está terminando. [...] Y si ya no le dan, están muriendo todo. ¿Nuestros niños en qué van a quedar? Hemos estado en 
eso. Por eso nosotros hemos venido a presentar el Mandato, exigiendo al presidente para que nos ayude a no continuar abriendo los pozos petroleros en la Amazonía, ni en nuestros territorios. [...] La empresa no apoya en nada, solo causa muerte. [...] La gente está muriendo como perros. (S. Aranda, comunicación personal, 14 de marzo de 2018)

A continuación, se analizará el Mandato de las Mujeres Amazónicas Defensoras De la Selva de las Bases frente al Extractivismo a través de los testimonios de estas dirigentes y lideresas. De sus palabras y sentires podemos hacernos una ligera idea de lo que significa para estas mujeres la palabra desarrollo y sus promesas de bienestar y paz. Y decimos ligera idea para llamar la atención sobre los límites que puede tener nuestra imaginación o empatía con una realidad cruel que muchas personas lectoras de este artículo no habrán vivido en carne propia. En este sentido, démonos cuenta de que en la corporalidad de las Mujeres Amazónicas están impresas las superposiciones de jurisdicción, de territorialidad y los diferentes tipos de violencia que se ejercen para imponer un modelo de desarrollo que devasta la vida.

El Mandato comienza considerando que se especifica "que el Estado ecuatoriano es suscriptor de importantes convenios y declaraciones internacionales en materia de derechos de pueblos indígenas como: el Convenio 169 de la oit, la Declaración de las Naciones Unidas sobre los derechos de los pueblos indígenas, la Declaración Americana sobre los Derechos de los Pueblos Indígenas y la Constitución del Ecuador" (Mujeres Amazónicas, 2018, p. 1). Por ello, se insta al Gobierno a que recuerde que en su Constitución está establecido que todos estos derechos serán de inmediato cumplimiento y aplicación. Se recuerda, también, el deber de respeto al derecho a la autodeterminación de los pueblos y nacionalidades indígenas y a lo establecido en la sentencia de la Corte Interamericana de Derechos Humanos (2012) del caso Sarayaku vs. Ecuador, en materia de consulta previa, libre e informada y consentimiento (Mujeres Amazónicas, 2018, p. 1). Con este comienzo, las Mujeres Amazónicas recuerdan al ejecutivo su obligación de respetar su propio sistema jurídico y le exigen el cumplimiento de sus responsabilidades desde el formalismo que sus parámetros monistas exigen. 
Después de esta introducción, las Mujeres Amazónicas comienzan a exponer el conjunto de violencias que le han ejercido, para intentar con ello imponerles un modelo de desarrollo que desprecian. En primer lugar, exponen que los procesos de consulta previa que se han realizado en sus comunas, comunidades y pueblos han sido un "[...] proceso totalmente viciado y manipulado por la Secretaría de Hidrocarburos" (Mujeres Amazónicas, 2018, p. 1). Es por ello que exigen que dichas consultas no sean tomadas en consideración. Como puso de manifiesto Catalina Chumpi dirigente shuar de la Coordinadora de Organizaciones de las Nacionalidades Amazónicas del Pastaza:

Nosotros no queremos la consulta. Porque sin consultar en nuestros territorios vinieron y se asentaron ahí, para decir que ya fuimos a consultar y aquí están. Solamente vinieron a dar los talleres y ahí anotaron y dijeron ya consultamos. ¡Gran mentira de las autoridades! Nosotros fuimos esa vez que entró en Chapinza, nos sentamos con el gobernador y dijimos aquí no están consultando. Si no saca a su gente que están ahí con las carpas, nosotros no respondemos. (C. Chumpi, comunicación personal, 13 de marzo de 2018)

Asimismo, se denuncia el irrespeto que han sufrido las organizaciones de las nacionalidades por parte del Gobierno Nacional, al cual se le acusa de crear dirigencias paralelas afines a sus intereses desarrollistas, de estimular acciones violentas en contra de las mujeres lideresas, de desalojar y amedrentar a familias enteras mediante la militarización de los territorios para facilitar la entrada de las empresas extractivas y de criminalizar y perseguir a las y los líderes que se opusieron a tales proyectos desarrollistas (Mujeres Amazónicas, 2018, pp. 1-2). Por todas estas prácticas y por el irrespeto a los instrumentos jurídicos señalados, las Mujeres Amazónicas denuncian que no han sido respetados sus derechos en el marco de la Ronda Suroriente y de la licitación de sus bloques petroleros junto con la ampliación del bloque 10 y en las concesiones mineras a las empresas Ecua Corriente S.A. (ECSA), Lowell, Ecuasolidos, Belarusian Oil Company, Andes Petroleum y celec ep (Mujeres Amazónicas, 2018, p. 1). Así lo afirmó Sandra Tukup, presidenta shuar de la Comunidad Chiwias del Cantón Logrońo, Morona Santiago: 
Y hay muchos niños en ese desalojo que hubo, hay muchos niños que fallecieron cuando las mamás fueron perseguidas y se entraron en las montańas y nacieron esos niños. Pero esos niños se murieron todos, no se salvaron, se murieron porque no había un aseo [...] se murieron todos los niños allá porque no tenían ni ropa, ni nada. Entonces esa es una violencia que es un caso como un crimen que se ha dado a los niños inocentes. También fueron fallecido algunas personas perseguidas. [...] Y también están militares y policías en esta zona que no pueden andar con tranquilidad ni niños ni mujeres. Son violadas, los niños amenazados. Y también hay muchos líderes y lideresas que están perseguidos y amenazados de muerte. Nosotros necesitamos una amnistía y una protección y los compañeros que han fallecido ahí por defensa del territorio, por ejemplo, el compañero Luis Tiwiram, el compañero José Tendeza, el compañero Bosco Bisun, y otros compańeros, que no se ha dado esa justicia. A la nacionalidad shuar se han muerto sin justicia y no hay justicia para estas personas que han fallecido por la defensa de nuestros territorios. ( $\mathrm{S}$. Tukup, comunicación personal, 22 de marzo de 2018)

A partir de la exposición de los considerandos referidos, las Mujeres Amazónicas (2018) demandan el cumplimiento de su Mandato, que se expresa en un total de veintidós puntos. El primero de ellos es precisamente el rechazo a los contratos y cualquier firma de acuerdo para el acceso de las empresas extractivas (petroleras, mineras, hidroeléctricas, madereras) en sus territorios, sean cuales sean los dirigentes o representantes de los Gobiernos Autónomos Descentralizados (GADs) que han otorgado su consentimiento. Estos contratos y acuerdos se consideran por ellas como ilegales e ilegítimos. En esta línea, por tanto, se exige "[...] la anulación de los contratos y/o convenios y concesiones otorgadas por el gobierno ecuatoriano a las empresas petroleras y mineras en el centro sur de la Amazonía" y que sus territorios sean declarados "libres de actividades extractivas" (punto 2) (Mujeres Amazónicas, 2018, p. 2).

En materia petrolera ello supone principalmente el rechazo total a la licitación de los dieciséis bloques que conforman la XI Ronda y a la ampliación de las operaciones de la empresa Agip Oil en el bloque 10 (puntos 3 y 6); pero también la exigencia de que sean declarados nulos los contratos de los bloques 79, 83, 74, 75 y 28 ya concesionados (punto 4), máxime cuando afectan a los nacimientos de 
las cuencas hidrográficas (puntos 7 y 9). Asimismo, también se exige el cierre de toda fuente de contaminación de los territorios indígenas de los pueblos Siecopay, Siona, Cofán, Kichwa, Shuar, Waorani y campesinos de la Amazonía Norte, con la correspondiente reparación integral de los mismos y con el pago por deuda ecológica e indemnizaciones respectivas por los daños causados (punto 8). Finalmente, se hace mención especial a la exigencia de que no sean ampliadas las operaciones petroleras y madereras en el Parque Nacional Yasuní por ser este un territorio ancestral de los tagaere, taromenanes y waoranis; con ello se garantizaría la supervivencia y se evitaría el etnocidio de los pueblos en aislamiento voluntario (punto 10) (Mujeres Amazónicas, 2018, pp. 2-3).

El territorio kichwa de Cuenca Villano es uno de los que más han sufrido las consecuencias de la actividad extractiva. El Bloque 10 fue concesionado por veinte años hace unos veintiocho, pero aún sigue en actividad y pretende su ampliación. La empresa que opera en la zona es Agip, una empresa italiana que, según el Ministro de Hidrocarburos, es todo un ejemplo a seguir: "el caso del Bloque 10 es una de las actividades mejor llevadas en cuanto a lo social y ambiental y eso son cosas que estamos revisando periódicamente" (Pérez, 2018). Esa no es la opinión de las mujeres que vienen representadas por su dirigente, Salomé Aranda, ni por las otras dirigentes que han oído y conocido la situación de su territorio. Esta intervención del Ministro de Hidrocarburos causó un cambio palpable en el rostro de la dirigenta de las nueve comunidades que forman la comuna de Moretecocha, pero como esta no estaba en la agenda de la audiencia, la indignación fue trasladada al presidente de la República y al Ministro de Hidrocarburos por Nina Gualinga, lideresa del pueblo Sarayaku, con estas palabras que trascribimos en su totalidad:

El seńor ministro de petróleo, hidrocarburos. Me gustaría que mire el rostro de estas mujeres, porque yo he visto que cuando estas mujeres hablan usted está mirando el papel. Por favor, tome, mire las caras de estas mujeres. Mire el rostro de la señora Salomé que está sentada acá, que vive en el bloque 10. Usted dice que el bloque 10 es el bloque donde mejor se ha manejado la explotación petrolera, ¿sabes lo que han vivido estas mujeres? Los niños están enfermos, están con granos, están con cáncer, nacen con cáncer desde el vientre de la madre. Las mujeres que viven ahí han sido víctimas de violaciones, han sido 
violadas en las chacras, han sido violadas cuando han ido a pedir arroz con donde los hombres que trabajan en las compañías petroleras porque ya no hay comida, porque ya no hay peces en los ríos, ya no da la yuca, ya no da el plátano, ya no hay animales. ¿Y usted está negando esta realidad diciendo que se ha manejado muy bien la explotación petrolera ahí? Eso no es verdad y aquí están las testigas, aquí estamos las que estamos viviendo eso. Aquí están las mujeres que, por defender sus derechos, por defender sus familias, sus territorios, el futuro de sus hijos, de nuestros hijos, de mi hijo que tiene un año, están siendo amenazadas de muerte, están siendo perseguidas, están siendo amenazadas, hostigadas de cualquier forma. Tome y mire el rostro de estas mujeres, ¿con qué cara les dice que todo se ha manejado bonito? ¿Con qué cara si usted no vive ahí? Yo le pregunto ¿y no eres capaz de mirar el rostro de estas mujeres? (N. Gualinga, comunicación personal, 22 de marzo de 2018)

Por su parte, en materia minera, supone asimismo la exigencia de que sean declarados nulos los contratos, convenios y concesiones en los territorios de Warints, Nankints, Panantza, Tundayme, Kutuku, Shaimi y Cóndor Mirador (todos ellos en las provincias de Morona Santiago y Zamora Chinchipe, al sur de la Amazonía); sobre todo los relativos a las concesiones de empresas como Ecuacorrientes (ECSA), Ecuasolidos y Lowell que afectan a territorios ancestrales shuar, achuar y saraguros, así como a población campesina afincada en esa zona (puntos 11 y 12). También, se rechaza la construcción hidroeléctrica de la empresa CELEC EP en la provincia de Morona Santiago. Finalmente $-\mathrm{y}$ dada la violencia ejercida por el Gobierno Nacional para defender los intereses mineros - se exige que sea retirada toda presencia militar y policial de los territorios indígenas señalados, así como que sea dada la amnistía a los compañeros shuar que fueron desalojados y perseguidos por defender sus territorios (puntos $17 \mathrm{y}$ 18). Se nombran —entre otros - a Angel Nantip, Domingo Ankuash, José Esach, Luis Tiwiram, Esteban Pandam y Pepe Acacho. Finalmente, se exige que el Estado pida disculpa y sanciones a los responsables de las muertes de los líderes Bosco Wisum, Fredy Taish y José Tendetza (punto 19) (Mujeres Amazónicas, 2018, pp. 3-4).

Al respecto podemos recordar las palabras de Nelly Wampash, dirigente política de la FISCH: 
Mi petición es, señor presidente, es el caso San Carlos Pananza, Nankintzs, donde hubo desalojos. Y en ese desalojo, hubo algunos casos de persecución, criminalización de hombres, mujeres desalojadas embarazadas y soy una de las mujeres que el esposo está perseguido. Tengo un hijo de un mes. El embarazo sufrí. Fui a ver a mi esposo a la selva. Estuvo enfermo. Llevé medicinas con todo el esfuerzo, dejando a mis hijos. Por eso señor presidente estoy aquí pidiendo la amnistía de mi esposo y de los compañeros que no están aquí. Que no ha sido la posibilidad de venir todas las mujeres que venimos de un lugar muy lejano, donde tienen que caminar dos días, tres días, en canoa. $(\mathrm{N}$. Wampash, comunicación personal, 22 de marzo de 2018).

Por otro lado, las Mujeres Amazónicas (2018) declaran en el quinto punto de su Mandato su rechazo a las socializaciones o consultas para cualquier proyecto extractivo, ya que - en el ejercicio de su derecho a la autodeterminación- en sus propios espacios de decisión ya han resuelto que no quieren proyectos de este tipo en sus territorios. Además, añaden que estas supuestas socializaciones y consultas "no cumplen ni cumplirán con los estándares internacionales de la consulta y consentimiento previo, libre e informado como lo establece la sentencia del caso Sarayaku vs. el Gobierno ecuatoriano" y que son el motivo de la generación de conflictos internos en las comunidades, que arriesgan la supervivencia de grupos vulnerables como el Pueblo Sapara, los pueblos en aislamiento voluntario y a las mujeres de todas las nacionalidades de la Amazonía (Mujeres Amazónicas, 2018, p. 2).

En este sentido, también se exige el respeto por las propias estructuras organizativas de los pueblos y nacionalidades indígenas y por la otorgación de nombramientos de la dirigencia de estas, sin que la Secretaría de la Gestión de la Política intervenga de modo alguno en estos espacios (punto 15). Esta exigencia de respeto se extiende a las organizaciones de mujeres que se constituyen bajo el derecho propio y consuetudinario, y al amparo del derecho a la autodeterminación (punto 16) (Mujeres Amazónicas, 2018, pp. 3-4).

Finalmente, los puntos 14, 20, 21 y 22 del Mandato se refieren a la exigencia de toma de medidas por parte del ejecutivo para garantizar la seguridad y protección de las 
mujeres lideresas y sus familias, las cuales son amenazadas por defender los derechos humanos y de la Naturaleza. Tal es el caso, de entre otras, de Patricia Gualinga (lideresa de Sarayaku), Nema Grefa (presidenta de la Nación Sapara), Alicia Cahuiya (lideresa waorani), Gloria Ushigua (lideresa sapara), Margoth Escobar (activista por los derechos de la Naturaleza) y Salomé Aranda (lideresa kichwa de la Comuna Moretecocha, cuya persona y familia fueron amenazadas tras su denuncia pública de violaciones y abusos sexuales perpetrados por empleados de la Empresa Agip Oil que opera en la zona). Aquí reproducimos como algunas de las líderes explican al presidente Lenin Moreno estas amenazas y presiones a sus vidas.

Cuando nosotros con mi hermano nos opusimos a la explotación petrolera en nuestro territorio fuimos perseguidos, incluso había boletos de captura. También lo mismo con la compañera Patricia Gualinga que ha sido amenazada. Hay varios casos de amenaza. Yo solo quiero decir eso, que quede el petróleo bajo tierra en nuestro territorio y que se respeten los derechos del pueblo sapara para no desaparecer. (G. Ushigua, comunicación personal, 12 de marzo de 2018)

Yo el día cinco de enero fui amenazada de muerte y eso ha sido muy público, porque yo he puesto la denuncia. Y varias mujeres de aquí han sido amenazadas también y consideramos que esta raíz de haber alzado nuestra voz honesta con el tema de tratar de salvar los territorios que vivimos. (P. Gualinga, comunicación personal, 22 de marzo de 2018)

Además, se exigen investigaciones profundas, históricas y estadísticas sobre los casos de violencia física, sexual y de género (incluida la prostitución) asociadas con las actividades extractivas (mineras, petroleras, madereras, etc.) y a la militarización de los territorios. Esto con el objetivo de que sean aplicadas las sanciones necesarias a los culpables, se brinden garantías de no-repetición y para que se cree y ponga en práctica una política pública adecuada al contexto amazónico y a cada situación concreta de las comunas, comunidades y pueblos en los que viven las mujeres firmantes de este Mandato. Para acabar, y como último punto, se exige el cumplimiento de los derechos constitucionales de no-discriminación y se requiere para ello de la 
realización de políticas públicas contra la discriminación de las personas indígenas (Mujeres Amazónicas, 2018, pp. 3-4).

Las últimas palabras de este Mandato son las siguientes: "nosotros las Mujeres Amazónicas aquí firmantes, exigimos el cumplimiento de nuestro mandato, y daremos seguimiento del mismo" (Mujeres Amazónicas, 2018, p. 4). Y es ahí donde al día de hoy las Mujeres Amazónicas continúan luchando por la vida en sus territorios y defendiendo sus tierras, sus modos de vida en armonía con la Naturaleza y sus sistemas jurídicos frente al extractivismo y la mercantilización de la vida propia del modelo de desarrollo convencional-economicista y del derecho del Estado que lo avala.

\section{ConClusiones}

De la lectura y análisis del Mandato de las Mujeres Amazónicas podemos concluir que el desarrollo no hace sino llevar violencia a los territorios. Con la pretensión de profundizar o instaurar el neoextractivismo en territorios ancestrales toma forma un conflicto que podemos entender como conflicto jurídico (por la superposición de sistemas jurídicos que pretenden la regulación de un espacio), como conflicto de territorialidades (por la disputa entre lógicas territoriales y subjetividades encontradas que se persiguen hacer valer en un mismo espacio y que son incompatibles) y como conflicto entre modos de vida diametralmente opuestos (profundización del modelo de desarrollo convencional-economicista frente a alternativas al desarrollo o, si se prefiere, modos de vida en armonía con la Naturaleza).

Estos tres conflictos $-\mathrm{o}$ dimensiones del conflicto- no se entienden de manera separada el uno del otro y ponen de manifiesto que, lejos de fomentar la paz (aunque sea de manera imperfecta), en los territorios indígenas se crea toda una serie de dinámicas y prácticas violentas que son incompatibles con toda noción de tranquilidad. Las entrevistas ponen sobre la mesa el estado de alerta y amenaza que la Ronda Suroriente y las licitaciones mineras en el Norte, Centro y Sur de la Amazonía causan en los cuerpos y sentires de las Mujeres Amazónicas. Estas, con sus palabras, nos transmiten su íntima conexión con la Naturaleza, al ser ellas las encargadas de las labores de cuidados y del 
cultivo de las chacras. No obstante, esta conexión no se limita únicamente a su rol como cuidadoras de la vida (en sentido amplio) y al ejercicio de actividades reproductivas, sino que además hay una fuerte relación a nivel espiritual, identitario y de continuidad cultural por la transmisión de conocimientos a su descendencia.

Además, ha quedado reflejado en el análisis del Mandato que las actividades extractivas en sus territorios destruyen las economías de subsistencia, en las que están al frente las mujeres, al contaminar los suelos y el agua. También, producen graves enfermedades que afectan en gran medida a las mujeres y los nińos y nińas, ya que son ellas junto con sus hijos las que se encargan de las labores de cuidado y del cultivo, estando en mayor contacto con alimentos y agua contaminada. Por otro lado, al ser las mujeres las encargadas de las actividades reproductivas, hay una mayor carga de trabajo, ya que son ellas las que cuidan de las personas enfermas y las que deben hacer mayores esfuerzos en las chacras, que pierden productividad. Todas estas situaciones, además de por supuesto el aumento de las violaciones, de los abusos sexuales (y el miedo a ello) y de la prostitución, colocan a las Mujeres Amazónicas en general en un contexto de violencia constante, donde sufren y desfallecen emocionalmente por muy firmes y duras que se consideren, ya que, objetivamente, toda su rutina se desenvuelve en un ambiente hostil y de amenaza constante.

La Ronda Suroriente es un viejo fantasma que de a poco vuelve otra vez. Hemos conocido su historia con cierto detalle, pero esta es únicamente otra amenaza más que hay que sumar a otras bondades del desarrollo. Hablamos de diferentes proyectos como carreteras, hidroeléctricas, industria maderera, monocultivos, minería (aunque a esta hemos hecho alusión en el análisis del Mandato) y otras actividades económicas expansivas que — junto a la Ronda Suroriente — se intentan imponer en territorios ancestrales de los pueblos indígenas. En este contexto se nos plantea la pregunta: ¿es posible hablar de un futuro de paz en estos territorios ancestrales? Partiendo del análisis del Mandato de las Mujeres Amazónicas Defensoras de la Selva de las bases frente al Extractivismo y de la atención a los testimonios de las dirigentes y lideresas realizado, podemos concluir que sí; sí es posible la existencia de paz en los territorios ancestrales del Norte, Centro y Sur de la Amazonía ecuatoriana. No obstante, este escenario de paz —entendiendo siempre esta paz como imperfecta- será posible toda vez que el Estado ecuatoriano respete y haga respetar el Convenio 169 de 
la оiт, la Declaración de las Naciones Unidas sobre los derechos de los pueblos indígenas, la Declaración Americana sobre los Derechos de los Pueblos Indígenas, la jurisprudencia sobre la materia de la Corte Interamericana de Derechos Humanos (especialmente la sentencia de 27 de junio de 2012, Pueblo Indigena Kichwa de Sarayaku vs. Ecuador) y los derechos de los pueblos indígenas y de la Naturaleza reconocidos en la Constitución del Ecuador.

En suma, la paz o la construcción de esta es posible en la Amazonía ecuatoriana, pero para ello es condición sine qua non que el Estado respete y garantice los derechos colectivos de los pueblos indígenas, reconocidos en los instrumentos de derechos humanos internacionales, regionales y en su propia Constitución.

\section{REFERENCIAS}

Acción Ecológica. (2018). Consulta previa, libre e informada, jno más socialización! Recuperado de https://rebelion.org/consulta-previa-libre-e-informada-no-mas-socializacion/

Acosta, A. (2013). El Buen Vivir. Sumak Kawsay, una oportunidad para imaginar otros mundos. Barcelona: Icaria-Antrazyt.

Agencia EFE. (20 de diciembre de 2019). Ronda petrolera, internet masivo y concesiones, en metas de Ecuador para 2020. Recuperado de https://www.efe.com/efe/america/ economia/ronda-petrolera-internet-masivo-y-concesiones-en-metas-de-ecuador-para-2020/20000011-4136490

Álvarez-Lugo, Y. (2017). Derechos territoriales indígenas, pluralismo jurídico y alternativas al desarrollo: notassobreunarelaciónindisoluble.DeustoJournalofHumanRights, 2. Recuperado de https://www.academia.edu/41519575/Derechos_territoriales_ind\%C3\%ADgenas_ pluralismo_jur\%C3\%ADdico_y_alternativas_al_desarrollo_notas_sobre_una_ relaci\%C3\%B3n_indisoluble

Andes. (25 deenero de 2016). Ecuadory consorciochino Andes Petroleum firman dos contratos de exploración en la Amazonía. Recuperado de https:/www.andes.info.ec/es/noticias/economia/16/ ecuador-consorcio-chino-andes-petroleum-firman-dos-contratos-exploracion-amazonia 
Código Orgánico de la Función Judicial. Registro Oficial Suplemento 544, Quito, Ecuador, 9 de marzo de 2009.

Constante, S. (18 de octubre de 2013). Mujeres indígenas se manifiestan en Quito contra la explotación natural. El País, recuperado de https:/elpais.com/internacional/2013/10/18/ actualidad/1382067876_357276.html

Constitución de la República del Ecuador. Registro Oficial No. 499, Quito, Ecuador, 20 de octubre de 2008.

Corte Interamericana de Derechos Humanos. (2012). Sentencia de 27 de junio de 2012 (Fondo y Reparaciones). Pueblo Indigena Kichwa de Sarayaku Vs. Ecuador. Recuperado de http://www.corteidh.or.cr/docs/casos/articulos/seriec_245_esp.pdf

Cunha, Teresa (2019). Cuando las mujeres ya no pueden dormir: Una critica feminista al Desarrollo extractivista contemporáneo [Archivo de video]. Hegoa Multimedia. Recuperado de http://multimedia.hegoa.ehu.eus/es/videos/116

Dos retos en el sector petrolero. (6 de diciembre de 2019). El Comercio, recuperado de https:// www.elcomercio.com/opinion/editorial/opinion-editorial-retos-sector-petrolero.html

El Ciudadano. (15 de diciembre de 2013). La clausura de Fundación Pachamama se ampara en Estado de Derecho. Recuperado de http://www.elciudadano.gob.ec/ la-clausura-de-fundacion-pachamama-se-ampara-en-un-estado-de-derecho/

El Telégrafo. (27 de noviembre de 2013). Mañana se presentan ofertas de la Ronda Sur Oriente. Disponible en: https://www.eltelegrafo.com.ec/noticias/economia/4/ manana-se-presentan- ofertas-de-la-ronda-sur-oriente

El Universo. (2018, febrero 27). Ronda Petrolera Suroriente se lanzaría en el segundo trimestre del 2018. Recuperado de: https://www.eluniverso.com/noticias/2018/02/27/ nota/6643450/ronda-petrolera-suroriente-se-lanzaria-segundo-semestre-2018 Fecha de consulta: 6 de abril de 2018 . 
Escobar, A. (2012). Más allá del desarrollo: postdesarrollo y transiciones hacia el pluriverso. Revista de Antropología Social, 21, 23-62.

Esteva, G. (2009). Más allá del Desarrollo: la buena vida. Revista América Latina en Movimiento, $445,1-5$.

Gobierno e indígenas sellan nuevos acuerdos. (12 de diciembre de 2017). El Comercio, recuperado de http://www.elcomercio.com/actualidad/gobierno-ecuador-indigenas-acuerdos-mineria.html

Gobierno ecuatoriano busca inversión petrolera asiática para la Amazonía, pese a protestas. (25 de marzo de 2013). Diario El Norte, recuperado de https://www.elnorte.ec/gobierno-ecuatoriano-busca-inversion-petrolera-asiatica-para-la-amazonia-pese-a-protestas/

Harvey, D. (2005). El “nuevo" imperialismo: acumulación por desposesión. Buenos Aires: Clacso. Recuperado de http://biblioteca.clacso.org.ar/clacso/se/20130702120830/harvey.pdf

Hernández-Cervantes, A. (2014). La producción jurídica de la globalización económica: notas de una pluralidad jurídica transnacional. Ciudad de México: Centro de Estudios Jurídicos y Sociales Mispar, Universidad Autónoma de San Luis Potosí, Universidad Nacional Autónoma de México.

Hernández-Zubizarreta, J. (2015). El tratado internacional de los pueblos para el control de las empresas transnacionales. Revista de Relaciones Laborales Lan Harremanak, 33(II), 209-226.

Indígenas protestan por XI ronda petrolera en el Sur Oriente. (28 de noviembre de 2013). La República, recuperado de https://www.larepublica.ec/blog/politica/2013/11/28/ indigenas-protestan-xi-ronda-petrolera-sur-oriente/

Jiménez, J. (2018). Evolución humana y paz. Una aproximación desde la teoría y la práctica. Revista vínculos de historia, 7, 15-36.

Ley Orgánica de Educación Superior. Registro Oficial Suplemento No. 298, Quito, Ecuador, 12 de octubre de 2010. 
Ley Orgánica de Garantías Constitucionales y Control Jurisdiccional. Registro Oficial Suplemento No. 52, Quito, Ecuador, 22 de octubre de 2009.

Ley Orgánica de Tierras Rurales y Territorios ancestrales. Registro Oficial Suplemento No. 711, 14 de marzo de 2016.

Ley Orgánica para la Planificación Integral de la Circunscripción Territorial Especial Amazónica. Registro Oficial Suplemento No. 245, 21 de mayo de 2018.

Melo, M. (2012). La nueva ronda petrolera y el derrumbe del paradigma constitucional. En G. M. Benavides Llerena y M. G. Chávez Núñez (eds.), Horizonte de los derechos humanos (pp. 103-117). Quito: Universidad Andina Simón Bolívar. Recuperado de http:// repositorio.uasb.edu.ec/bitstream/10644/4124/1/Melo-La\%20nueva.pdf

Mujeres Amazónicas. (2018). Mandato de las Mujeres Amazónicas Defensoras de la Selva de las bases frente al Extractivismo. Recuperado de https://www.ocmal.org/mandato-de-lasmujeres-amazonicas-defensoras-de-la-selva-de-las-bases-frente-al-extractivismo/

Muñoz, F. (2001). La paz imperfecta. Granada: Universidad de Granada.

Precio del petróleo mejora en el 2020 tras conflicto entre Irán y Estados Unidos. (4 de enero de 2020). El Universo, recuperado de https://www.eluniverso.com/noticias/2020/01/04/ nota/7674834/petroleo-precio-crisis-medio-oriente-iran-estados-unidos

Pueblo Originario Kichwa de Sarayaku (2018). Kawsak Sacha. Recuperado de https://kawsaksacha.org/es/

Puente, D. (4 de julio de 2017). Moreno entregará sede de la Conaie en comodato para los próximos 100 años. El Comercio, recuperado de http://www.elcomercio.com/actualidad/ politica-leninmoreno-conaie-comodato-sede.html Fecha de consulta: 6 de abril de 2018; y en El Comercio (2017, septiembre 12). Gobierno y Conaie definieron agenda común de trabajo. Disponible en: http://www.elcomercio.com/actualidad/gobierno-conaie-agenda-comun-dialogo.html Fecha de consulta: 6 de abril de 2018. 
Reglamento para la Ejecución de la Consulta Previa, Libre e Informada en los Procesos de Licitación y Asignación de Áreas y Bloques Hidrocarburíferos. Decreto Ejecutivo (1247), Quito, Ecuador, 19 de julio de 2012.

Rist, G. (2002). El desarrollo: historia de una creencia occidental. Madrid: Catarata

Secretaría de Hidrocarburos. (2013a). Ecuador Southeastern Round: Technical, legal, economic, and socio-environmental aspects. Recuperado de http://www.secretariahidrocarburos.gob. ec/wp-content/uploads/2013/04/RONDA-SURORIENTE-ECUADOR-ENGLISHrevision-enero-2013.pdf

Secretaría de Hidrocarburos. (2018). Nuevas Rondas Petroleras en el Ecuador: un proceso de cambio. Recuperado de http://www.secretariahidrocarburos.gob.ec/wp-content/ uploads/2018/02/Nuevas-Rondas3-4.peso-reducido.pdf

Senplades. (2007). Secretaría Nacional de Planificación y Desarrollo. Plan Nacional de Desarrollo 2007-2010: Planificación para la Revolución Ciudadana. Quito. Recuperado de https://www.planificacion.gob.ec/wp-content/uploads/downloads/2013/09/Plan-Nacional-Desarrollo-2007-2010.pdf

Senplades. (2009). Plan Nacional para el Buen Vivir 2009-2013: Construyendo un Estado Plurinacional e Intercultural. Quito. Recuperado de: https://www.planificacion.gob.ec/ wp-content/uploads/downloads/2012/07/Plan_Nacional_para_el_Buen_Vivir.pdf

Senplades. (2013). Plan para el Buen Vivir 2013-2017: Todo el mundo mejor. Quito. Recuperado de: https://observatorioplanificacion.cepal.org/sites/default/files/plan/files/Ecuador\%20Plan\%20Nacional\%20del\%20Buen\%20Vivir.pdf

Senplades. (2017). Plan Nacional de Desarrollo 2017-2021: Toda una vida. Quito. Recuperado de: https://www.planificacion.gob.ec/wp-content/uploads/downloads/2017/10/ PNBV-26-OCT-FINAL_0K.compressed1.pdf 
Sieder, R. (2015). Indigenous peoples rights and the law in Latin America. En C. Rodríguez Garavito (ed.), Law and Society in Latin America: A new map (pp. 1- 19). Nueva York: Routledge Taylor \& Francis Group a GlassHouse Book.

Svampa, M. (2013). "Consenso de las Commodities" y lenguajes de valoración en América Latina. Nueva Sociedad, 244. Recuperado de https://www.academia.edu/5061391/ Consenso_de_los_commodities

Ulloa, A. (2014). Territorios y Conflictos en el contexto del Neoextractivismo en América Latina [Archivo de video]. Recuperado de http://ecapio.org/video/territorios-y-conflictos-enel-contexto-del-neoextractivismo-en-america-latina/?f=tag:bergbau

Vallejo-Real, I. y García-Torres, M. (2017). Mujeres indígenas y neo-extractivismo petrolero en la Amazonía centro del Ecuador: Reflexiones sobre ecologías y ontologías políticas en articulación. Revista Brújula, 11, 1-43.

Yrigoyen, R. (2015). The panorama of pluralist constitutionalism: From multiculturalism to decolonization. En C. Rodríguez Garavito (ed.), Law and Society in Latin America: A new map (pp. 157-174). Nueva York: Routledge Taylor \& Francis Group a GlassHouse Book.

\section{Referencias de los testimonios}

Almeida, Alexandra. (2018). Experta en Hidrocarburos de la organización Acción Ecológica. Entrevista realizada el 7 de abril de 2018 en la sede de Acción Ecológica. Quito, Ecuador.

Aranda, Salomé. (2018a). Dirigente kichwa de la Mujer de la Comuna Moretecocha. Entrevista realizada el 14 de marzo de 2018 en la Plaza de la Independencia. Quito, Ecuador.

Cahuiya, Alicia. (2018a). Lideresa waorani y ex vicepresidenta de la NAwE. Entrevista realizada el 12 de marzo de 2018 en la Plaza de la Independencia. Quito, Ecuador.

Cahuiya, Alicia. (2018b). Intervención en el Foro de las Mujeres Amazónicas celebrado en el Paraninfo de la Universidad Andina Simón Bolívar el 12 de marzo de 2018. Quito, Ecuador. 
Chumpi, Catalina. (2018a). Dirigenta shuar de la Coordinadora de Organizaciones de las Nacionalidades Amazónicas del Pastaza y presidenta de las siete nacionalidades de la Provincia de Pastaza. Entrevista realizada el 13 de marzo de 2018 en la Plaza de la Independencia. Quito, Ecuador.

Chumpi, Catalina. (2018b). Intervención en el Foro de las Mujeres Amazónicas celebrado en el Paraninfo de la Universidad Andina Simón Bolívar el 12 de marzo de 2018. Quito, Ecuador.

Gualinga, Nina. (2018). Lideresa del pueblo Sarayaku en su intervención en la audiencia con el presidente de la República celebrada el 22 de marzo de 2018 en el Palacio de la Carondelet. Quito, Ecuador.

Gualinga, Patricia. (2018b). Ex dirigenta kichwa del pueblo Sarayaku y actual asesora política del pueblo Sarayaku. Entrevista realizada el 22 de marzo de 2018 en la Plaza de la Independencia. Quito, Ecuador.

Pérez, Carlos. (2018). Ministro de Hidrocarburos en la audiencia con las Mujeres Amazónicas, celebrada el 22 de marzo de 2018 en el Palacio de la Carondelet. Quito, Ecuador.

Santi, Ena. (2018a). Lideresa kichwa del pueblo Sarayaku y ex dirigente de Mujeres del pueblo Sarayaku. Entrevista realizada el 15 de marzo de 2018 en la Plaza de la Independencia. Quito, Ecuador.

Tukup, Sandra. (2018a). Dirigente shuar presidenta de la comunidad Chiwias, del Cantón Logroño, Morona Santiago. Entrevista realizada el 22 de marzo de 2018 en la Plaza de la Independencia. Quito, Ecuador.

Ushigua, Gloria. (2018a). Presidenta de la Asociación de Mujeres Saparas. Entrevista realizada el 12 de marzo de 2018 en la Plaza de la Independencia. Quito, Ecuador.

Wampash, Nelly. (2018). Dirigenta política de la FISCH en su intervención en la audiencia con el presidente de la República celebrada el 22 de marzo de 2018 en el Palacio de la Carondelet. Quito, Ecuador. 